\title{
Phosphorylation and Fragmentation of the Cardiac Troponin T: Mechanisms, Role in Pathophysiology and Laboratory Diagnosis
}

\author{
Aleksey M. Chaulin, $\mathrm{PGS}^{1,2^{*}}$ \\ ISamara State Medical University \\ ${ }^{2}$ Samara Regional Clinical Cardiology Dispensary \\ Samara, the Russian Federation
}

\begin{abstract}
Cardiac troponin $\mathrm{T}(\mathrm{cTnT})$, a protein essential for calcium-regulated, myofibrillar ATPase activity, is extremely sensitive to the action of a significant number of intra- and extracellular enzymes, the action of which causes post-translational modifications (PTMs) of amino acid structure and functioning cTnT. PTMs of cTnT may play important roles in the regulation of cardiac contractility. The vast majority of cTnT modifications involve the phosphorylation by a variety of Ser/Thr kinases, including PKC. At the same time, the activity of cTnT phosphorylation can change under physiological conditions and in some cardiovascular diseases, including heart failure, acute myocardial infarction, and arrhythmias. Along with cTnT phosphorylation, cTnT fragmentation occurs, the activity of which can also change. This article discusses the mechanisms of cTnT phosphorylation and fragmentation, discusses the important role of these processes in the pathophysiology and laboratory diagnosis of some cardiovascular diseases, and notes promising directions for further research. (International Journal of Biomedicine. 2021;11(3):250-259.)
\end{abstract}

Key Words: cardiac troponin $\mathrm{T} \bullet$ phosphorylation $\bullet$ fragmentation $\bullet$ cardiovascular disease

For citation: Chaulin AM. Phosphorylation and Fragmentation of the Cardiac Troponin T: Mechanisms, Role in Pathophysiology and Laboratory Diagnosis. International Journal of Biomedicine. 2021;11(3):250-259. doi:10.21103/Article11(3)_RA2.

\section{Abbreviations}

AF, atrial fibrillation; AMI, acute myocardial infarction; ATP, adenosine triphosphate; ASK1, apoptosis signal-regulating kinase 1; AF, atrial fibrillation; CVD, cardiovascular disease; cTnT, cardiac troponin T; HF, heart failure; LV, left ventricle; $\mathbf{L V R}$, left ventricular remodeling; LVH, left ventricular hypertrophy; PTMs, post-translational modifications; PMA, phorbol 12-myristate 13-acetate; PKC, protein kinase C; PAK1, p21-activated kinase 1; PP2A, protein phosphatase 2A; ROCK, Rho-A-dependent kinase; RV, right ventricle; $\mathbf{T n}$, troponin; $\mathbf{T n} \mathbf{T}$, troponin $\mathrm{T} ; \mathbf{T m}$, tropomyosin.

$\mathrm{T}$ roponin ( $\mathrm{Tn}$ ) is essential in $\mathrm{Ca}^{2+}$-activated contraction of skeletal and cardiac muscles. Tn consists of three subunits ( $\mathrm{TnT}, \mathrm{TnC}$ and $\mathrm{TnI}$ ) and, together with $\mathrm{Tm}$, is located on the actin filament. ${ }^{(1)} \mathrm{TnC}$, the $\mathrm{Ca}^{+}$binding subunit, transduces $\mathrm{Ca}^{2+}$ signaling; TnI, the inhibitory subunit, inhibits myosin ATPase activity; and TnT, the tropomyosin binding subunit, anchors the Tn protein complex to the thin filament. ${ }^{(1)} \mathrm{cTnT}$ plays a pivotal regulatory role in the $\mathrm{Ca}^{2+}$-mediated interaction

*Corresponding author: Aleksey M. Chaulin, PGS. Samara State Medical University; Samara Russia. E-mail: alekseymichailovich22976@gmail.com between actin thin filament and myosin thick filament. At low cytosolic $\mathrm{Ca}^{2+}$ levels, the formation of the actomyosin complex is sterically inhibited by $\mathrm{TnI}$. The resting inhibitory state is rapidly transformed by the 100 -fold increase in intracellular $\mathrm{Ca}^{2+}$ concentration occurring as a consequence of sarcolemmal depolarization. At an increased cytosolic level, $\mathrm{Ca}^{2+}$ binds to $\mathrm{TnC}$ and induces a sequence of conformational changes in the $\mathrm{Tn}-\mathrm{Tm}$ complex that exposes the specific myosin-binding site on actin. Tm normally sterically blocks the interaction between myosin heads and actin. When $\mathrm{TnC}$ is saturated with $\mathrm{Ca}^{2+}$, the inhibition of myosin binding to actin by tropomyosin is reversed. This is apparently due to the small movement of Tm, 
caused by the dimensional changes in $\mathrm{TnC}$ upon $\mathrm{Ca}^{2+}$ binding that remove a steric block. The result is that myosin heads are able to contact actin, with formation of active actin-myosin cross-bridges and generation of contraction (Fig.1). ${ }^{(2,3)}$

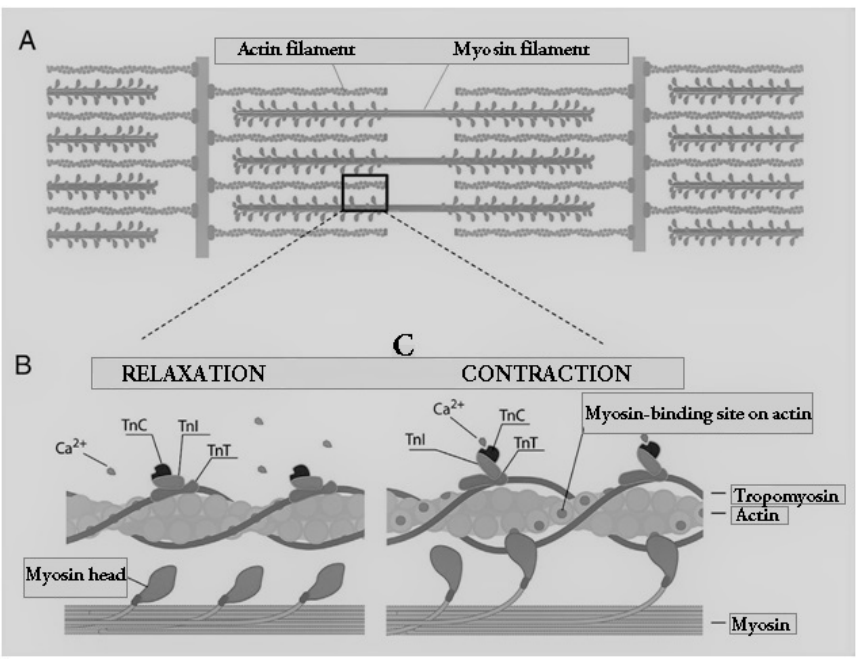

Fig.1. The structure and conformational changes in the Tn-Tm complex during contraction and relaxation

A-Sarcomere structure; $B$-Structure of a thin filament in the relaxation of cardiomyocytes; $C$-Structure of a thin filament in the contraction of cardiomyocytes

As a rule, the more $\mathrm{Ca}^{2+}$ that is able to bind to the thin filament, the higher the contraction force. An increase in the contractile ability of the heart can also lead to a higher force of contraction and allows more blood to be ejected during one stroke volume. ${ }^{(4)}$ Myofilaments have a variable sensitivity to $\mathrm{Ca}^{2+}$, which affects the binding of cTnC to $\mathrm{Ca}^{2+}$ ions and, accordingly, the contractility of the heart muscle. The higher sensitivity of myofilaments to $\mathrm{Ca}^{2+}$ leads to an earlier contraction in systole and a slower relaxation in diastole. Energy for heart contraction is provided by ATP, which is hydrolyzed by the enzyme ATPase in the myosin head. The enzymatic activity of ATPase correlates with the rate of the formation of cross-bridges and shortening of the sarcomere, the rate of energy consumption by cardiomyocytes, and with the average heart rate in different species. ${ }^{(5,6)}$

PTMs of key contractile proteins play an important role in regulating cardiac output and maintaining it in accordance with the body's needs. The most significant of these are the processes of protein phosphorylation under the influence of certain enzymes called kinases. Under the action of kinases, proteins are mainly phosphorylated on the following amino acids: serine (Ser), threonine (Thr), and tyrosine (Tyr). The exact molecular mechanisms of phosphorylation processes, as well as their effect on cardiac contractility, are still not fully understood. Researchers continue to discover new sites of phosphorylation and kinases, which not only play a physiological role, but are also of great importance in the pathogenesis of CVD (HF, AMI, and AF). ${ }^{(7)}$

Another important but less studied type of PTM is the cTnT fragmentation. The study of this process is important for the pathogenesis and laboratory diagnosis of CVD.
Under the conditions of various cardiac and non-cardiac pathological conditions, ${ }^{\left({ }^{8}-10\right)}$ which have an adverse effect on cardiomyocytes, the activity of proteolytic enzymes that cause the cleavage of cTnT into fragments can be enhanced. The development of antibodies directly to these fragments can increase the sensitivity of existing immunoassays and improve the early diagnosis of CVD. In addition, the size of these fragments is so small that it allows them to pass through structural components into other biological fluids, for example, saliva and urine, as has recently been demonstrated in several studies. ${ }^{(11-13)}$

This review examines the mechanisms of posttranslational phosphorylation and fragmentation of cTnT, and discusses the importance of these processes in the physiology and pathophysiology of cardiac muscle contractions, as well as in clinical laboratory diagnostics.

\section{$\underline{\text { Troponin } T \text { isoforms }}$}

Human TnT is encoded by three homologous genes (TNNT2, TNNT1, and TNNT3) and expressed as three isoforms: cardiac (cTnT), slow skeletal (ssTnT), and fast skeletal (fsTnT) muscle TnT, respectively. ${ }^{(14,15)}$

The three TnT isoforms are significantly diverged in the N-terminal region but highly conserved in the middle and C-terminal regions that contain binding sites for $\mathrm{TnC}$, TnI and Tm. ${ }^{(14,16)}$

In the studies of Anderson et al., ${ }^{(17)}$ it has been shown that cTnT is expressed in the human heart as four isoforms $\left(\mathrm{cTnT}_{1}\right.$ through $\mathrm{cTnT}_{4}$, numbered in the order of decreasing molecular size). cTnT1 and $\mathrm{cTnT}_{2}$ are expressed in the fetal heart, with $\mathrm{cTnT}_{2}$ being expressed at a very low level. $\mathrm{cTnT}_{4}$ is expressed in the fetal heart and is re-expressed in the failing adult heart, whereas $\mathrm{cTnT}_{3}$ is the dominant isoform in the adult heart. ${ }^{(17-19)}$

\section{Phosphorylation of cTnT: mechanisms, role in the physiology and pathophysiology of CVD}

Phosphorylation is a fundamental mechanism in regulating the structure and function of $\mathrm{cTnT}$. The earliest reports of cTnT phosphorylation date back to the 1980s, when the research groups of Villar-Palasi et al. ${ }^{(20)}$ and Guseva et al. ${ }^{(21)}$ identified certain features for cTnT phosphorylation, but researchers were unable to identify the enzyme responsible for this reaction. Subsequently, it was found that PKC is responsible for the phosphorylation of cTnT, and this was finally confirmed by in vitro studies. ${ }^{(22,23)}$ Noland et al.( ${ }^{22)}$ and Swiderek et al. ${ }^{(23)}$ incubated cTnTs derived from bovine myocardium with $\mathrm{PKC}$ for various periods of time. Researchers reported phosphorylation of various regions of cTnT after prolonged incubation with PKC. Using protein sequencing according to Edman's method, it was revealed that in addition to the Ser-2 site, multiple Ser and Thr residues (Thr204, Ser208, Thr213 and Thr294) are also phosphorylated by protein $\mathrm{PKC}$, especially $\mathrm{PKC} \alpha, \mathrm{PKC} \varepsilon$ and $\mathrm{PKC} \xi .^{(16,24-25)}$ Noland and $\mathrm{KuO}^{(26)}$ showed that the $\mathrm{Ca}^{2+}$-stimulated MgATPase of actomyosin containing phosphorylated cTnT, compared with that containing unphosphorylated $\mathrm{TnT}$, was decreased by up to $48 \%$. Phosphorylation of cTnT also decreased (up to $48 \%$ ) its maximum binding to Tm-F-actin. The authors concluded that 
the effects of phosphorylated $\mathrm{TnT}$ in decreasing actomyosin MgATPase might be secondary to its decreased interactions with the other components of the thin filament.

Several studies have investigated PKC-mediated, site-specific effects of cTnT phosphorylation. Thr197, Ser201, Thr206 and Thr287 in the C-terminal region of cardiac TnT were identified as functionally important PKC phosphorylation sites. ${ }^{(27-32)}$ Substitution of the Ser or Thr residue with Glu to mimic the negative charge introduced by PKC phosphorylation of cardiac TnT caused decreases in maximum force development and calcium sensitivity. M. Sumandea et al. ${ }^{(31)}$ found that Thr206 is a functionally critical cTnT PKC phosphorylation residue. Its exclusive phosphorylation by PKC- $\alpha$ or replacement by Glu (mimicking phosphorylation) significantly decreased maximum tension, actomyosin $\mathrm{Mg}$-ATPase activity, myofilament $\mathrm{Ca}^{2+}$ sensitivity, and cooperativity. It was also observed that PKC dependent phosphorylation of Thr206alone was sufficient to reduce maximum tension development. ${ }^{(24)}$

The PKC family consists of a number of different isozymes with different substrate specificities. ${ }^{(33,34)}$ Classical PKCs (isoforms $\alpha, \beta 1, \beta 2$, and $\gamma$ ) are activated by phosphatidylserine, $\mathrm{Ca}^{2+}$, and diacylglycerol (or PMA). Novel $\operatorname{PKCs}(\delta, \varepsilon, \eta, \theta$, and $\mu)$ are not activated by $\mathrm{Ca}_{2}^{+}$but are activated by PMA and diacylglycerol. The atypical PKCs $(\zeta$, 1 , and $\lambda$ ) are not activated by $\mathrm{Ca}^{2+}$, PMA, or diacylglycerol. $(35,36) \mathrm{PKC} \alpha$ directly phosphorylates regulatory myofilament

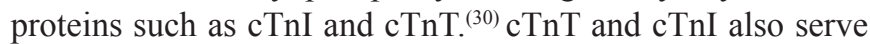
as targets for PKC $\varepsilon{ }^{\left({ }^{(37)}\right.}$ Jideama NM et al. ${ }^{(30)}$ showed that PKC isozymes $\alpha, \delta, \epsilon$, and $\zeta$ displayed distinct substrate specificities in phosphorylating $\mathrm{TnI}$ and $\mathrm{TnT}$ subunits in the bovine cardiac troponin complex. Thus, PKC- $\alpha,-\delta$, and $-\epsilon$ phosphorylated $\mathrm{TnI}$ more than TnT, but PKC- $\zeta$ conversely phosphorylated the latter more than the former.

However, S. Wu and R. Solaro ${ }^{(38)}$ identified the atypical $\mathrm{PKC} \zeta$ isoform to associate specifically with $\mathrm{cTnI}$ in untreated adult rat ventricular cardiac myocytes. According to several studies, the most common PKC isoform present in adult ventricular myocytes, $\mathrm{PKC} \varepsilon$, interacts with both $\mathrm{cTnI}$ and cTnT. ${ }^{(37,39-41)}$

The various effects of PKC isoforms can be attributed to several factors. First, some PKC isoforms have a number of other intracellular targets, the activation of which can subsequently neutralize the main phosphorylating effect of PKC on cTnT and cTnI. Thus, it was shown that PKCל is also involved in the Pak1/PP2A pathway leading to Thr dephosphorylation of $\mathrm{cTnI}$ and $\mathrm{cTnT} .^{(38-41)}$ These data indicate that the activation of $\mathrm{PKC} \zeta$ is a significant control mechanism regulating both phosphorylation and dephosphorylation of myofilament proteins. Second, the authors used various methods of phosphorylation, which could also affect the results obtained. In particular, in vitro phosphorylation is based on incubation in buffers containing purified protein kinases but lacking other components - other intracellular kinase targets and dephosphorylation components (phosphatase enzymes). In situ studies are carried out by activating the expression of phosphorylation enzymes in viable cardiomyocytes, in which many other kinase targets are present. This may be the main reason for the opposite results, such as a decrease in phosphorylation of troponin molecules. As shown in a study by Wu et al., ${ }^{(38)}$ protein kinases activate additional targets and phosphatases. Dephosphorylation can work as a compensatory mechanism to reverse the decreased contractility resulting from the phosphorylation of $\mathrm{cTnT}$ and $\mathrm{cTnI}$.

Jideama et al. ${ }^{(30)}$ discovered unique evidence that PP1, a serine/threonine protein phosphatase, effectively dephosphorylated $\mathrm{TnT}$ and $\mathrm{TnI}$ in the thin filament. The authors revealed that while PKC and PKA phosphorylation decreased the $\mathrm{Ca}^{2+}$-stimulated $\mathrm{Mg}^{2+}$ ATPase activities of the rat cardiac myofibrils, PP1 dephosphorylation restored it close to that of the control values. PP1 does not have a specific target site for dephosphorylation of cTnT; however, the Thr213 site is the least sensitive to the action of PP1, while the PP2A enzyme specifically targets it, ${ }^{(36,42)}$ which suggests a different role for the two phosphatases. Based on the above, it becomes obvious that the phosphorylation-dephosphorylation reactions are subject to fine regulation to maintain the optimal contractile function of the myocardium and the corresponding oxygen requirements of the body.

It has also been reported that kinases other than PKC are also involved in phosphorylation of cTnT. ASK1, highly expressed in cardiac muscle, is an important mediator in the signaling pathways induced by tumor necrosis factor interleukin-1, and ROS. ${ }^{(43,44)} \mathrm{He}$ et al. ${ }^{(44)}$ showed that ASK1 plays an important role in the regulation of cardiac contractile function by phosphorylating cTnT and may participate in cytokine/ROS-induced pathogenesis of cardiomyopathy and heart failure. In particular, ASK1 phosphorylates $\mathrm{cTnT}$ at sites T194 and S198 within an ASK1 consensus phosphorylation sequence (although other sites may also be phosphorylated). Vahebi et al. ${ }^{(45)}$ found that ROCK-II induced a depression in maximum ATPase rate and tension, which was associated with phosphorylation of TnT, TnI, and myosin-binding protein C. Mass spectrometric analysis demonstrated that ROCK-II phosphorylated cTnI at S23, S24, and T144 and cTnT at S278 and T287 sites. Pfleiderer et al. ${ }^{(46)}$ showed that Raf-1, a serinethreonine protein kinase, acts as a selective cTnT-Thr ${ }^{206}$ kinase; Raf does not phosphorylate cTnI. These data identify Rafdependent cTnT-Thr206 phosphorylation as a novel mechanism that would link growth factor-dependent signaling pathways to dynamic changes in cardiac contractile function. Table 1 summarizes the known data on $\mathrm{cTnT}$ phosphorylation.

Phosphorylation of cTnT may play an important role in the pathophysiology of CVD and in laboratory diagnosis. Given that the in vitro-measured effects of cTnT phosphorylation usually indicate a decrease in myofilament contractility (Table 1) and that PKC activity increases in response to hypertrophic signaling and in heart failure, ${ }^{(47,48)}$ it can be assumed that cTnT phosphorylation is a characteristic feature of these pathological conditions. Belin et al. ${ }^{(49)}$ studied molecular mechanisms that explain interventricular differences in myofilament function in experimental congestive HF induced in rats. PKC- $\alpha-$ dependent phosphorylation of $\mathrm{cTnI}$ and $\mathrm{cTnT}$ was greater in failing LV myofilaments than in failing RV myofilaments. In failing RVs, total cTnI and cTnT phosphoprotein levels were significantly increased by $\sim 50 \%$, relative to controls $(P<0.05)$. 
In failing LVs, total cTnT and cTnI phosphorylation levels were increased by $\sim 50 \%(P=0.053)$ and $102 \%(P<0.05)$, respectively, relative to controls. Phosphorylation of cTnT at Thr206 was increased $87 \%$ in failing RV muscles and $24 \%$ in failing LV muscles, compared to control.

A number of researchers have conducted several studies to analyze the phosphorylation of contractile proteins after AMI. ${ }^{(50-52)}$ Using a rat model of MI and phosphoproteomic technology, Dubois et al. ${ }^{(53)}$ discovered that remodeling is associated with decreased levels of myocardial and plasma Ser208-phosphorylated TnT. To confirm the association in human plasma, the new specific polyclonal antibodies against human/rat Ser(207/208)-phosphorylated TnT were used to test plasma obtained from patients in the first week after MI, with low, intermediate, and high LVR a year later. The study found a significant decrease of Ser207-phosphorylated TnT and of the Ser207-phosphorylated TnT/total TnT ratio in those with intermediate or high LVR. An increase in TnT phosphorylation was also found in $\mathrm{AF} .{ }^{(54)}$

In addition, increased activity of PP1 and PP2A was also noted in patients with $\mathrm{AF}^{(54,55)}$. This may indicate the formation of a specific compensatory mechanism, namely, that the increased activity of PP1 and PP2A counteracts the effects of kinases (phosphotransferases). Table 2 summarizes the data on cTnT phosphorylation in pathological conditions.

\section{Fragmentation of cTnT: mechanisms, significance in laboratory diagnosis and pathophysiology of CVD}

cTnT is sensitive not only to the action of kinases and phosphatases, but also to the action of many proteases, which can change their activity under certain physiological and pathological conditions. Proteolytic modifications of cTnT and $\mathrm{cTnI}$ have been shown to have pathological effects on myocardial contractility. ${ }^{(56,57)}$ Communal et al. ${ }^{(58)}$ examined whether caspase- 3 cleaved cardiac myofibrillar proteins and, if so, whether it affects contractile function. When cTnT, cTnI, and $\mathrm{cTnC}$ were incubated individually with caspase-3, there was no detectable cleavage. However, when the recombinant troponin complex was exposed to caspase-3, cTnT was cleaved, resulting in fragments of $25 \mathrm{kDa}$. This destructive modification of cardiac TnT decreased the maximum myosin ATPase activity and myofibril force generation. ${ }^{(58)}$

Mu-calpain is a myofibril-associated protease and is known to degrade TnT. TnT is known as a protein with extended conformation, in which the $\mathrm{NH} 2$-terminal variable region is a part of the "tail" domain of troponin. This region does not contain binding sites for other thin-filament proteins, but alteration of its structure affects the $\mathrm{Ca} 2+$ regulation of muscle contraction. ${ }^{(59)}$ A study on restricted proteolytic modification of cTnT represents a new area of research and will provide valuable information to further understand the role of post-translational regulation in cardiac muscle function and diseases. Zhang et al. ${ }^{(59)}$ reported production of the $\mathrm{NH} 2$-terminal truncated cardiac $\mathrm{TnT}\left(\mathrm{cTnT}-\mathrm{ND}_{72-291}\right.$ ) during myocardial ischemia-reperfusion. Mu-calpain treatment of the cardiac myofibril and troponin complex specifically reproduced cTnT-ND. In contrast, mucalpain treatment of isolated cardiac $\mathrm{TnT}$ resulted in nonspecific degradation, suggesting that this structural modification is relevant to the physiological structures of the myofilament.

Di Lisa et al. ${ }^{\left({ }^{(6)}\right)}$ showed that mu-calpain was at least ten times more active than m-calpain in degrading $\mathrm{TnI}$ and $\mathrm{TnT}$ both in vitro and in situ. It is interesting that phosphorylation by PKC resulted in a twofold increase in the degradation of TnI.

A restricted proteolysis of cardiac TnT was recently found ${ }^{(27)}$ to be a novel regulatory mechanism in physiological and pathophysiological adaptations of the cardiac muscle. Different from the destructive cleavage by caspase 3 , this restrictive proteolysis selectively removes only the $\mathrm{N}$-terminal variable region and preserves the conserved regions of cardiac TnT. Experimental data have shown that selectively removing the N-terminal variable region does not destroy the function of $\mathrm{TnT}$ but alters the binding affinities for TnI, TnC and Tm. ${ }^{(61)}$ Previous studies by several laboratories showed that selective removal of the $\mathrm{N}$-terminal variable region of $\mathrm{TnT}$ slightly decreased the maximum myosin ATPase activity and myofibril force generation without affecting thin-filament calcium sensitivity and cooperativity. ${ }^{(27,62-64)}$

Cardiac necrosis in AMI is accompanied by the release of various proteolytic enzymes from lysosomes. It is generally accepted that $\mathrm{cTnI}$ is very sensitive to proteolysis. The appearance of immunoreactive cTnI fragments in human serum after AMI has been confirmed by several groups of researchers. ${ }^{(65-68)}$ Degradation and changes in cTnI have implications for the immunoreactivity of antibodies used in various clinical analyses. ${ }^{(67-69)}$ This leads to different results when measuring the same serum sample with different $\mathrm{cTnI}$ immunoassays that have different anti-cTnI antibodies, which complicates the clinical interpretation of these measurements.

$\mathrm{cTnT}$ is an acknowledged biomarker of AMI that is known to be prone to proteolytic degradation in serum. Several studies devoted to the analysis of cTnT from serum samples of AMI patients revealed a set of proteolytic fragments with apparent molecular masses of $29,19,18$, and $16-\mathrm{kDa}$, with the $29-\mathrm{kDa}$ fragment being the predominant form. ${ }^{(70-74)}$ Fragmentation of cTnT in the blood serum of AMI patients was shown by different groups using gel filtration chromatography ${ }^{(68)}$ and immunoblots. ${ }^{(70,73,75)}$

Cardinaels et al. ${ }^{(73)}$ demonstrated that the Roche cTnT immunoassay detects intact as well as degraded cTnT forms in AMI patients' sera during the period of diagnostic testing. Intact cTnT rapidly disappears from the circulation during the early hours after AMI, but immunoreactive fragments remain present longer. These results are consistent with Michielsen et al., ${ }^{(70)}$ who found that intact $\mathrm{cTnT}$ rapidly disappears from the circulation during the early hours after AMI, but immunoreactive fragments remain present longer.

Extensive fragmentation of cTnT has also been found in the serum of patients with end-stage chronic renal failure. ${ }^{(71,72)}$ It is likely that in chronic renal failure these fragments accumulate due to a decrease in clearance, which may lead to an overestimation of the cTnT concentration. ${ }^{(71,76,77)}$ In the multi-ethnic Chronic Renal Insufficiency Cohort (CRIC), high sensitivity (Hs)-TnT was detectable in $81 \%$ of subjects. In addition, lower eGFR was associated with higher expected hs-TnT. Pervan et al. ${ }^{(11)}$ showed that kidneys are the main organ of elimination of troponin from blood. 
Table 1.

cTnT phosphorylation: mechanisms and physiological effects

\begin{tabular}{|c|c|c|c|c|}
\hline Phosphorylation site & Enzyme & Object and type of study & Physiological effect & Source \\
\hline $\begin{array}{l}\text { Thr190, Thr199, } \\
\text { Thr280 }\end{array}$ & PKC & Bovine heart, in vitro & Not studied & [22] \\
\hline $\begin{array}{l}\text { Thr 190, Thr 194, } \\
\text { Thr 199, Thr } 280\end{array}$ & $\begin{array}{l}\text { PKC- } \alpha, \text { PKC- } \delta \text {, } \\
\text { PKC- } \varepsilon, \text { PKC- } \zeta\end{array}$ & Bovine heart, in vitro & $\begin{array}{l}\text { Phosphorylation of TnT by PKC- } \alpha \\
\text { yielded marked decreases in both } \\
\text { Ca2 }+ \text { sensitivity and activity of } \\
\text { MgATPase Phosphorylation by } \\
\text { PKC- } \zeta \text { at distinct, unknown sites } \\
\text { resulted in a slightly increased Ca2+ } \\
\text { sensitivity without affecting the } \\
\text { activity of MgATPase. }\end{array}$ & {$[30]$} \\
\hline Thr 194, Ser 198 & ASK1 & $\begin{array}{l}\text { Human heart, in vitro / } \\
\text { Rat heart, in situ }\end{array}$ & $\begin{array}{l}\text { Overexpression of ASK1 induces } \\
\text { cTnT phosphorylation and inhibits } \\
\text { contractility in cardiomyocytes }\end{array}$ & [44] \\
\hline $\begin{array}{l}\text { Thr197, Ser201, } \\
\text { Thr206, Thr287 }\end{array}$ & PKC- $\alpha$ & Mouse heart, in vitro & $\begin{array}{l}\text { Thr206 exclusive phosphorylation by } \\
\text { PKC-alpha significantly decreased } \\
\text { maximum tension, actomyosin Mg- } \\
\text { ATPase activity, myofilament Ca2+ } \\
\text { sensitivity, and cooperativity. }\end{array}$ & [31] \\
\hline Thr206 & Raf-1 & Rat heart, in vitro & $\begin{array}{l}\text { Raf-dependent cTnT-Thr206 } \\
\text { phosphorylation was found to be a } \\
\text { novel mechanism that would link } \\
\text { growth factor-dependent signaling } \\
\text { pathways to dynamic changes in } \\
\text { cardiac contractile function. }\end{array}$ & [46] \\
\hline Ser278, Thr287 & ROCK-II & Mouse heart, in vitro & $\begin{array}{l}\text { A depression in maximum ATPase } \\
\text { rate and tension }\end{array}$ & {$[45]$} \\
\hline
\end{tabular}

Table 2.

Data on cTnT phosphorylation in pathological conditions

\begin{tabular}{|c|c|c|c|}
\hline $\begin{array}{l}\text { Pathological } \\
\text { condition }\end{array}$ & Object and type of study & Changes in cTnT phosphorylation and possible effects & Source \\
\hline $\mathrm{HF}$ & Failing human LV tissue & $\begin{array}{l}\text { The altered thin-filament function in human failing } \\
\text { myocardium was associated with PKC-mediated } \\
\text { phosphorylation of TnT. }\end{array}$ & {$[47]$} \\
\hline $\mathrm{HF}$ & Mouse model & $\begin{array}{l}\text { The prolonged effect of PKC } \varepsilon \text { overexpression for } 6 \\
\text { months brings a decrease in the Ca2 } 2+\text { sensitivity of the } \\
\text { myofilaments. The decrease in Ca2+ sensitivity correlates } \\
\text { with increased cTnI/cTnT phosphorylation. }\end{array}$ & {$[48]$} \\
\hline $\begin{array}{l}\text { Congestive } \\
\text { HF }\end{array}$ & Rat model & $\begin{array}{l}\text { Expression and activation of PKC- } \alpha \text { was increased } \\
\text { twofold in failing RV myocardium and relative to the RV. } \\
\text { Phosphorylation of cTnI and cTnT by PKC- } \alpha \text { was } \\
\text { greater in failing LV myofilaments than in failing RV } \\
\text { myofilaments. }\end{array}$ & [49] \\
\hline AMI & Pig model & $\begin{array}{l}\text { No differences in cTnT phosphorylation were found } \\
\text { between sham and MI hearts }\end{array}$ & {$[52]$} \\
\hline AMI & Plasma of patients with AMI & $\begin{array}{l}\text { A decreased TnT- Ser207-phosphorylation was found in } \\
\text { patients with high LVR after AMI }\end{array}$ & {$[53]$} \\
\hline $\mathrm{AF}$ & $\begin{array}{l}\text { Cardiomyocytes from human } \\
\text { right atrialappendages }\end{array}$ & An increase in TnT phosphorylation was found in $\mathrm{AF}$ & {$[54]$} \\
\hline
\end{tabular}


Table 3.

Data on the pathophysiological and laboratory significance of PTMs (phosphorylation and fragmentation) in $C V D$

\begin{tabular}{|c|c|c|}
\hline PTM & Pathophysiological and laboratory significance & Source \\
\hline $\begin{array}{l}\text { TnT phosphorylation and } \\
\text { CVD pathophysiology }\end{array}$ & $\begin{array}{l}\text { PKC-dependent phosphorylation of cTnT was found to be } \\
\text { increased in cardiac hypertrophy and HF } \\
\text { A decreased TnT-Ser207-phosphorylation was found in } \\
\text { patients with high LVR after AMI } \\
\text { An increase in TnT phosphorylation was found in AF. } \\
\text { Increased activity of PP1 and PP2A was noted in patients with } \\
\text { AF that may indicate the formation of a specific compensatory } \\
\text { mechanism, namely, that the increased activity of PP1 and } \\
\text { PP2A counteracts the effects of kinases. }\end{array}$ & $\begin{array}{c}\text { [47], [48], [49] } \\
\text { [53] }\end{array}$ \\
\hline $\begin{array}{l}\text { TnT phosphorylation and } \\
\text { Lab tests in CVD }\end{array}$ & $\begin{array}{l}\text { LVR wass associated with decreased levels of myocardial and } \\
\text { plasma Ser208-phosphorylated TnT. }\end{array}$ & {$[53]$} \\
\hline $\begin{array}{l}\text { Fragmentation of cTnT } \\
\text { and Lab tests in CVD }\end{array}$ & $\begin{array}{l}\text { Fragmentation of cTnT in the blood serum of AMI patients was } \\
\text { shown by different groups using gel filtration chromatography } \\
\text { and immunoblots. }\end{array}$ & $\begin{array}{l}{[68],[70],[73]} \\
{[75]}\end{array}$ \\
\hline $\begin{array}{l}\text { Fragmentation of cTnT } \\
\text { and Lab tests in CVD }\end{array}$ & $\begin{array}{l}\text { The 29-kDa fragment of cTnT in AMI serum samples mainly } \\
\text { appears due to the cleavage by thrombin during serum sample } \\
\text { preparation. }\end{array}$ & [78] \\
\hline
\end{tabular}

Along with the well-studied cTnT degradation by the action of mu-calpain, there are other candidates for that role. The results of the study by Katrukha et al. ${ }^{(78)}$ suggest that the 29-kDa fragment of cTnT in AMI serum samples mainly appears due to the cleavage by thrombin during serum sample preparation. Apart from thrombin, some other protease(s) cause the further degradation of the 29-kDa fragment to form 16-19$\mathrm{kDa}$ fragments in serum. ${ }^{(73,74)}$ Katrukha et al. ${ }^{(78)}$ highlighted that the knowledge of sites of cTnT degradation is very important, both (a) for the selection of the antibodies that are not affected by thrombin-mediated cTnT proteolysis; and (b) for the selection of the proper matrix to be used for cTnT measurements. The development of immunoassays specifically aimed at detecting intact, fragmented, or phosphorylated cTnT can help in studying the pathophysiology of degradation of cTnT and, accordingly, lead to improved laboratory diagnosis of CVD. ${ }^{(79-86)}$

Table 3 summarizes the data on the pathophysiological and clinical and laboratory significance of PTMs (phosphorylation and fragmentation) of cTnT.

\section{Conclusion}

The Tn-Tm complex is an important regulatory protein complex that is required to maintain the contractile ability of the heart. The Tn-Tm complex changes dynamically and adapts to meet the necessary needs of the body. According to most studies, phosphorylation of cTnT reduces the activity of ATPase, decreases the maximum tension of myofilaments and decreases sensitivity to $\mathrm{Ca} 2+$ ions, which leads to a decrease in myocardial contractility. Changes in cTnT phosphorylation may play an important role in the pathogenesis of CVD, including HF, AMI, and AF. Thus, in $\mathrm{HF}$, there is an increased expression of PKC and a subsequent increase in cTnT phosphorylation, which ultimately leads to a gradual decrease in myocardial contractility. Quite remarkable are the observations that the phosphorylation of cTnT in the heart correlates with the phosphorylation of circulating cTnT in plasma after AMI, which may be a predictor of the development of LV remodeling and can be used as such in laboratory diagnostics. Because of their cardiac specificity, cTnI and cTnT are actively used as biomarkers of myocardial alteration in AMI and HF. One of the promising areas for further research is the processes of fragmentation of cTnT into smaller fragments that can pass through hematotissue barriers into biological fluids obtained by non-invasive methods (urine and saliva), which will help expand the pool of specific immunoassays with high diagnostic value.

\section{Competing Interests}

The author declares that there is no conflict of interest regarding the publication of this article.

\section{References}

1. Takeda S, Yamashita A, Maeda K, Maéda Y. Structure of the core domain of human cardiac troponin in the $\mathrm{Ca}(2+)$ saturated form. Nature. 2003 Jul 3;424(6944):35-41. doi: 10.1038 /nature 01780 .

2. Gomes AV, Potter JD, Szczesna-Cordary D. The role 
of troponins in muscle contraction. IUBMB Life. 2002 Dec;54(6):323-33. doi: 10.1080/15216540216037.

3. Filatov VL, Katrukha AG, Bulargina TV, Gusev NB. Troponin: structure, properties, and mechanism of functioning. Biochemistry (Mosc). 1999 Sep;64(9):969-85.

4. Solaro RJ. Integration of myofilament response to $\mathrm{Ca} 2+$ with cardiac pump regulation and pump dynamics. Am J Physiol. 1999 Dec;277(6 Pt 2):S155-63. doi: 10.1152/ advances.1999.277.6.S155.

5. Rouslin $\mathrm{W}, \mathrm{Broge} \mathrm{CW}$. Isoform-independent heart raterelated variation in cardiac myofibrillar $\mathrm{Ca}(2+)$-activated $\mathrm{Mg}(2+)$-ATPase activity. Am J Physiol. 1996 May;270(5 Pt1):C1271-6. doi: 10.1152/ajpcell.1996.270.5.C1271.

6. Moreira CM, Meira EF, Vestena L, Stefanon I, Vassallo DV, Padilha AS. Tension cost correlates with mechanical and biochemical parameters in different myocardial contractility conditions. Clinics (Sao Paulo). 2012;67(5):489-96. doi: 10.6061/clinics/2012(05)14.

7. Dong X, Sumandea CA, Chen YC, Garcia-Cazarin ML, Zhang J, Balke CW, Sumandea MP, Ge Y. Augmented phosphorylation of cardiac troponin I in hypertensive heart failure. J Biol Chem. 2012 Jan 6;287(2):848-57. doi: 10.1074/ jbc.M111.293258.

8. Chaulin AM, Svechkov NA, Volkova SL, Grigoreva YV. [Diagnostic value of cardiac troponins in elderly patients without myocardial infarction]. Modern Problems of Science and Education. 2020;6. doi: 10.17513/spno.30302. [Article in Russian].

9. Chaulin AM, Duplyakov DV. [Increased cardiac troponins, not associated with acute coronary syndrome. Part 1]. Cardiology: News, Views, Education. 2019;7(2):13-23. doi: 10.24411/2309-1908-2019-12002. [Article in Russian].

10. Chaulin A.M., Duplyakov D.V. [Increased cardiac troponins, not associated with acute coronary syndrome. Part 2]. Cardiology: News, Views, Education. 2019;7(2):24-35. doi: 10.24411/2309-1908-2019-12003. [Article in Russian].

11. Pervan P, Svagusa T, Prkacin I, Savuk A, Bakos M, Perkov S. Urine high sensitive Troponin I measuring in patients with hypertension. Signa Vitae. 2017;13:62-64. doi: $10.22514 / \mathrm{sv} 133.062017 .13$

12. Chaulin AM, Duplyakova PD, Bikbaeva GR, Tukhbatova AA, Grigorieva EV, Duplyakov DV. Concentration of highsensitivity cardiac troponin I in the oral fluid in patients with acute myocardial infarction: a pilot study. Russian Journal of Cardiology. 2020;25(12):3814. doi: 10.15829/1560-40712020-3814. [Article in Russian].

13. Chaulin AM, Karslyan LS, Bazyuk EV, Nurbaltaeva DA, Duplyakov DV. [Clinical and Diagnostic Value of Cardiac Markers in Human Biological Fluids]. Kardiologiia. 2019 Dec 11;59(11):66-75. doi: 10.18087/cardio.2019.11.n414. [Article in Russian].

14. Jin JP, Zhang Z, Bautista JA. Isoform diversity, regulation, and functional adaptation of troponin and calponin. Crit Rev Eukaryot Gene Expr. 2008;18(2):93-124. doi: 10.1615/ critreveukargeneexpr.v18.i2.10.

15. Perry SV. Troponin T: genetics, properties and function. J Muscle Res Cell Motil. 1998 Aug;19(6):575-602. doi: 10.1023/a:1005397501968.

16. Wei B, Jin JP. TNNT1, TNNT2, and TNNT3: Isoform genes, regulation, and structure-function relationships. Gene. 2016 May 10;582(1):1-13. doi: 10.1016/j.gene.2016.01.006.
17. Anderson PA, Greig A, Mark TM, Malouf NN, Oakeley AE, Ungerleider RM, Allen PD, Kay BK. Molecular basis of human cardiac troponin $\mathrm{T}$ isoforms expressed in the developing, adult, and failing heart. Circ Res. 1995 Apr;76(4):681-6. doi: 10.1161/01.res.76.4.681.

18. Mesnard-Rouiller L, Mercadier JJ, Butler-Browne G, Heimburger M, Logeart D, Allen PD, Samson F. Troponin $\mathrm{T}$ mRNA and protein isoforms in the human left ventricle: pattern of expression in failing and control hearts. J Mol Cell Cardiol. 1997 Nov;29(11):3043-55. doi: 10.1006/ jmcc.1997.0519.

19. Duplyakov DV, Chaulin AM. [Mutations of heart troponines, associated with cardiomyopathies]. Cardiology: News, Views, Education. 2019;7(3):8-17. doi: 10.24411/23091908-2019-13001. [Article in Russian].

20. Villar-Palasi C, Kumon A. Purification and properties of dog cardiac troponin T kinase. J Biol Chem. $1981 \mathrm{Jul}$ 25;256(14):7409-15.

21. Gusev NB, Barskaya NV, Verin AD, Duzhenkova IV, Khuchua ZA, Zheltova AO. Some properties of cardiac troponin T structure. Biochem J. 1983 Jul 1;213(1):123-9. doi: 10.1042/bj2130123.

22. Noland TA Jr, Raynor RL, Kuo JF. Identification of sites phosphorylated in bovine cardiac troponin I and troponin $\mathrm{T}$ by protein kinase $\mathrm{C}$ and comparative substrate activity of synthetic peptides containing the phosphorylation sites. J Biol Chem. 1989 Dec 5;264(34):20778-85.

23. Swiderek K, Jaquet K, Meyer HE, Schächtele C, Hofmann F, Heilmeyer LM Jr. Sites phosphorylated in bovine cardiac troponin T and I. Characterization by 31P-NMR spectroscopy and phosphorylation by protein kinases. Eur J Biochem. 1990 Jul 5;190(3):575-82. doi: 10.1111/j.1432-1033.1990. tb15612.x.

24. Katoh N, Wise BC, Kuo JF. Phosphorylation of cardiac troponin inhibitory subunit (troponin I) and tropomyosinbinding subunit (troponin $\mathrm{T}$ ) by cardiac phospholipidsensitive Ca2+-dependent protein kinase. Biochem J. 1983 Jan 1;209(1):189-95. doi: 10.1042/bj2090189.

25. Dubois-Deruy E, Belliard A, Mulder P, Bouvet M, SmetNocca C, Janel S, Lafont F, Beseme O, Amouyel P, Richard $\mathrm{V}$, Pinet $\mathrm{F}$. Interplay between troponin $\mathrm{T}$ phosphorylation and $\mathrm{O}-\mathrm{N}$-acetylglucosaminylation in ischaemic heart failure. Cardiovasc Res. 2015 Jul 1;107(1):56-65. doi: 10.1093/cvr/ cvv136.

26. Noland TA Jr, Kuo JF. Protein kinase C phosphorylation of cardiac troponin $\mathrm{T}$ decreases $\mathrm{Ca}(2+)$-dependent actomyosin MgATPase activity and troponin $\mathrm{T}$ binding to tropomyosinF-actin complex. Biochem J. 1992 Nov 15;288 ( Pt 1)(Pt 1):123-9. doi: 10.1042/bj2880123.

27. Wei B, Jin JP. Troponin T isoforms and posttranscriptional modifications: Evolution, regulation and function. Arch Biochem Biophys. 2011 Jan 15;505(2):144-54. doi: 10.1016/j. abb.2010.10.013.

28. Sumandea MP, Burkart EM, Kobayashi T, De Tombe PP, Solaro RJ. Molecular and integrated biology of thin filament protein phosphorylation in heart muscle. Ann N Y Acad Sci. 2004 May;1015:39-52. doi: 10.1196/annals.1302.004.

29. Noland TA Jr, Kuo JF. Protein kinase C phosphorylation of cardiac troponin I or troponin $\mathrm{T}$ inhibits $\mathrm{Ca} 2(+)$-stimulated actomyosin MgATPase activity. J Biol Chem. 1991 Mar 15;266(8):4974-8. 
30. Jideama NM, Noland TA Jr, Raynor RL, Blobe GC, Fabbro D, Kazanietz MG, Blumberg PM, Hannun YA, Kuo JF. Phosphorylation specificities of protein kinase $\mathrm{C}$ isozymes for bovine cardiac troponin I and troponin $\mathrm{T}$ and sites within these proteins and regulation of myofilament properties. J Biol Chem. 1996 Sep 20;271(38):23277-83. doi: 10.1074/ jbc.271.38.23277.

31. Sumandea MP, Pyle WG, Kobayashi T, de Tombe PP, Solaro RJ. Identification of a functionally critical protein kinase $\mathrm{C}$ phosphorylation residue of cardiac troponin $\mathrm{T}$. J Biol Chem. 2003 Sep 12;278(37):35135-44. doi: 10.1074/ jbc.M306325200.

32. Sumandea MP, Vahebi S, Sumandea CA, Garcia-Cazarin ML, Staidle J, Homsher E. Impact of cardiac troponin T $\mathrm{N}$-terminal deletion and phosphorylation on myofilament function. Biochemistry. 2009 Aug 18;48(32):7722-31. doi: 10.1021/bi900516n.

33. Huang X, Walker JW. Myofilament anchoring of protein kinase C-epsilon in cardiac myocytes. J Cell Sci. 2004 Apr 15;117(Pt 10): 1971-8. doi: 10.1242/jcs.01044.

34. Steinberg SF. Cardiac actions of protein kinase $\mathrm{C}$ isoforms. Physiology (Bethesda). 2012 Jun;27(3):130-9. doi: 10.1152/physiol.00009.2012.

35. Bowling N, Walsh RA, Song G, Estridge T, Sandusky $\mathrm{GE}$, Fouts RL, et al. Increased protein kinase $\mathrm{C}$ activity and expression of $\mathrm{Ca} 2+$-sensitive isoforms in the failing human heart. Circulation. 1999 Jan 26;99(3):384-91. doi: 10.1161/01.cir.99.3.384.

36. Steinberg SF, Goldberg M, Rybin VO. Protein kinase C isoform diversity in the heart. J Mol Cell Cardiol. 1995 Jan;27(1):141-53. doi: 10.1016/s0022-2828(08)80014-4.

37. Xiao L, Zhao Q, Du Y, Yuan C, Solaro RJ, Buttrick PM. PKCepsilon increases phosphorylation of the cardiac myosin binding protein $\mathrm{C}$ at serine 302 both in vitro and in vivo. Biochemistry. 2007 Jun 12;46(23):7054-61. doi: 10.1021/ bi700467k.

38. Wu SC, Solaro RJ. Protein kinase C zeta. A novel regulator of both phosphorylation and de-phosphorylation of cardiac sarcomeric proteins. J Biol Chem. 2007;282(42):30691-8.

39. Buscemi N, Foster DB, Neverova I, Van Eyk JE. p21activated kinase increases the calcium sensitivity of rat triton-skinned cardiac muscle fiber bundles via a mechanism potentially involving novel phosphorylation of troponin I. Circ Res. 2002;91(6):509-16.

40. Ke Y, Wang L, Pyle WG, de Tombe PP, Solaro RJ. Intracellular localization and functional effects of P21-activated kinase-1 (Pak1) in cardiac myocytes. Circ Res. 2004 Feb 6;94(2):194-200. doi: 10.1161/01. RES.0000111522.02730.56.

41. Monasky MM, Taglieri DM, Patel BG, Chernoff J, Wolska BM, Ke Y, Solaro RJ. p21-activated kinase improves cardiac contractility during ischemia-reperfusion concomitant with changes in troponin- $T$ and myosin light chain 2 phosphorylation. Am J Physiol Heart Circ Physiol. 2012 Jan 1;302(1):H224-30. doi: 10.1152/ajpheart.00612.2011.

42. Jideama NM, Crawford BH, Hussain AK, Raynor RL. Dephosphorylation specificities of protein phosphatase for cardiac troponin I, troponin $\mathrm{T}$, and sites within troponin $\mathrm{T}$. Int J Biol Sci. 2006;2(1):1-9. doi: 10.7150/ijbs.2.1.

43. Gotoh Y, Cooper JA. Reactive oxygen species- and dimerization-induced activation of apoptosis signal- regulating kinase 1 in tumor necrosis factor-alpha signal transduction. J Biol Chem. 1998 Jul 10;273(28):17477-82. doi: 10.1074/jbc.273.28.17477.

44. He X, Liu Y, Sharma V, Dirksen RT, Waugh R, Sheu SS, Min W. ASK1 associates with troponin T and induces troponin $\mathrm{T}$ phosphorylation and contractile dysfunction in cardiomyocytes. Am J Pathol. 2003 Jul;163(1):243-51. doi: 10.1016/S0002-9440(10)63647-4.

45. Vahebi S, Kobayashi T, Warren CM, de Tombe PP, Solaro RJ. Functional effects of rho-kinase-dependent phosphorylation of specific sites on cardiac troponin. Circ Res. 2005 Apr 15;96(7):740-7. doi: 10.1161/01. RES.0000162457.56568.7d.

46. Pfleiderer P, Sumandea MP, Rybin VO, Wang C, Steinberg SF. Raf-1: a novel cardiac troponin T kinase. J Muscle Res Cell Motil. 2009;30(1-2):67-72. doi: 10.1007/s10974-0099176-y.

47. Noguchi T, Hünlich M, Camp PC, Begin KJ, El-Zaru M, Patten R, Leavitt BJ, Ittleman FP, Alpert NR, LeWinter MM, VanBuren P. Thin-filament-based modulation of contractile performance in human heart failure. Circulation. 2004 Aug 24;110(8):982-7. doi: 10.1161/01.CIR.0000139334.43109. F9.

48. Goldspink PH, Montgomery DE, Walker LA, Urboniene D, McKinney RD, Geenen DL, Solaro RJ, Buttrick PM. Protein kinase Cepsilon overexpression alters myofilament properties and composition during the progression of heart failure. Circ Res. 2004 Aug 20;95(4):424-32. doi: 10.1161/01. RES.0000138299.85648.92.

49. Belin RJ, Sumandea MP, Sievert GA, Harvey LA, Geenen DL, Solaro RJ, de Tombe PP. Interventricular differences in myofilament function in experimental congestive heart failure. Pflugers Arch. 2011 Dec;462(6):795-809. doi: 10.1007/s00424-011-1024-4.

50. Walker LA, Walker JS, Ambler SK, Buttrick PM. Stagespecific changes in myofilament protein phosphorylation following myocardial infarction in mice. J Mol Cell Cardiol. 2010 Jun;48(6):1180-6. doi: 10.1016/j.yjmcc.2009.09.010.

51. Avner BS, Shioura KM, Scruggs SB, Grachoff M, Geenen DL, Helseth DL Jr, Farjah M, Goldspink PH, Solaro RJ. Myocardial infarction in mice alters sarcomeric function via post-translational protein modification. Mol Cell Biochem. 2012 Apr;363(1-2):203-15. doi: 10.1007/s11010011-1172-z.

52. van der Velden J, Merkus D, de Beer V, Hamdani N, Linke WA, Boontje NM, Stienen GJ, Duncker DJ. Transmural heterogeneity of myofilament function and sarcomeric protein phosphorylation in remodeled myocardium of pigs with a recent myocardial infarction. Front Physiol. 2011 Nov 24;2:83. doi: 10.3389/fphys.2011.00083.

53. Dubois E, Richard V, Mulder P, Lamblin N, Drobecq H, Henry JP, Amouyel P, Thuillez C, Bauters C, Pinet F. Decreased serine207 phosphorylation of troponin $\mathrm{T}$ as a biomarker for left ventricular remodelling after myocardial infarction. Eur Heart J. 2011 Jan;32(1):115-23. doi: 10.1093/ eurheartj/ehq108.

54. Eiras S, Narolska NA, van Loon RB, Boontje NM, Zaremba R, Jimenez CR, Visser FC, Stooker W, van der Velden J, Stienen GJ. Alterations in contractile protein composition and function in human atrial dilatation and atrial fibrillation. J Mol Cell Cardiol. 2006 Sep;41(3):467-77. doi: 
10.1016/j.yjmcc.2006.06.072.

55. El-Armouche A, Boknik P, Eschenhagen T, Carrier L, Knaut M, Ravens U, Dobrev D. Molecular determinants of altered $\mathrm{Ca} 2+$ handling in human chronic atrial fibrillation. Circulation. 2006 Aug 15;114(7):670-80. doi: 10.1161/ CIRCULATIONAHA.106.636845.

56. Murphy AM, Kögler H, Georgakopoulos D, McDonough JL, Kass DA, Van Eyk JE, Marbán E. Transgenic mouse model of stunned myocardium. Science. 2000 Jan 21;287(5452):48891. doi: 10.1126/science.287.5452.488.

57. Colantonio DA, Van Eyk JE, Przyklenk K. Stunned periinfarct canine myocardium is characterized by degradation of troponin T, not troponin I. Cardiovasc Res. 2004 Aug 1;63(2):217-25. doi: 10.1016/j.cardiores.2004.04.006.

58. Communal C, Sumandea M, de Tombe P, Narula J, Solaro RJ, Hajjar RJ. Functional consequences of caspase activation in cardiac myocytes. Proc Natl Acad Sci U S A. 2002 Apr 30;99(9):6252-6. doi: 10.1073/pnas.092022999.

59. Zhang Z, Biesiadecki BJ, Jin JP. Selective deletion of the NH2-terminal variable region of cardiac troponin $\mathrm{T}$ in ischemia reperfusion by myofibril-associated mu-calpain cleavage. Biochemistry. 2006 Sep 26;45(38):11681-94. doi: 10.1021/bi060273s.

60. Di Lisa F, De Tullio R, Salamino F, Barbato R, Melloni E, Siliprandi N, Schiaffino S, Pontremoli S. Specific degradation of troponin $\mathrm{T}$ and I by mu-calpain and its modulation by substrate phosphorylation. Biochem J. 1995 May 15;308 ( Pt 1)(Pt 1):57-61. doi: 10.1042/bj3080057.

61. Biesiadecki BJ, Chong SM, Nosek TM, Jin JP. Troponin $\mathrm{T}$ core structure and the regulatory $\mathrm{NH} 2$-terminal variable region. Biochemistry. 2007 Feb 6;46(5):1368-79. doi: 10.1021/bi061949m.

62. Pan BS, Gordon AM, Potter JD. Deletion of the first 45 NH2-terminal residues of rabbit skeletal troponin $\mathrm{T}$ strengthens binding of troponin to immobilized tropomyosin. J Biol Chem. 1991 Jul 5;266(19):12432-8.

63. Fujita S, Maeda K, Maéda Y. Expression in Escherichia coli and a functional study of a beta-troponin $\mathrm{T} 25 \mathrm{kDa}$ fragment of rabbit skeletal muscle. J Biochem. 1992 Sep;112(3):306-8. doi: 10.1093/oxfordjournals.jbchem.a123896.

64. Chandra M, Montgomery DE, Kim JJ, Solaro RJ. The $\mathrm{N}$-terminal region of troponin $\mathrm{T}$ is essential for the maximal activation of rat cardiac myofilaments. J Mol Cell Cardiol. 1999 Apr;31(4):867-80. doi: 10.1006/jmcc.1999.0928.

65. Madsen LH, Christensen G, Lund T, Serebruany VL, Granger CB, Hoen I, Grieg Z, Alexander JH, Jaffe AS, Van Eyk JE, Atar D. Time course of degradation of cardiac troponin I in patients with acute ST-elevation myocardial infarction: the ASSENT-2 troponin substudy. Circ Res. 2006 Nov 10;99(10):1141-7. doi: 10.1161/01.RES.0000249531.23654. e1.

66. Madsen LH, Lund T, Grieg Z, Nygaard S, Holmvang L, Jurlander B, Grande P, Christensen G, Atar D. Cardiac troponin I degradation in serum of patients with hypertrophic obstructive cardiomyopathy undergoing percutaneous septal ablation. Cardiology. 2009;114(3):167-73. doi: 10.1159/000226596.

67. Katrukha AG, Bereznikova AV, Filatov VL, Esakova TV, Kolosova OV, Pettersson K, Lövgren T, Bulargina TV, Trifonov IR, Gratsiansky NA, Pulkki K, VoipioPulkki LM, Gusev NB. Degradation of cardiac troponin I: implication for reliable immunodetection. Clin Chem. 1998 Dec;44(12):2433-40.

68. Wu AH, Feng YJ, Moore R, Apple FS, McPherson PH, Buechler KF, Bodor G. Characterization of cardiac troponin subunit release into serum after acute myocardial infarction and comparison of assays for troponin T and I. American Association for Clinical Chemistry Subcommittee on cTnI Standardization. Clin Chem. 1998 Jun;44(6 Pt 1):1198-208.

69. Chaulin AM, Karslyan LS, Grigorieva EV, Nurbaltaeva DA, Duplyakov DV. Metabolism of cardiac troponins (Literature review). Complex Issues of Cardiovascular Diseases. 2019;8(4):103-115. [Article in Russian].

70. Michielsen EC, Diris JH, Kleijnen VW, Wodzig WK, Van Dieijen-Visser MP. Investigation of release and degradation of cardiac troponin $\mathrm{T}$ in patients with acute myocardial infarction. Clin Biochem. 2007 Aug;40(12):851-5. doi: 10.1016/j.clinbiochem.2007.04.004.

71. Diris JH, Hackeng CM, Kooman JP, Pinto YM, Hermens WT, van Dieijen-Visser MP. Impaired renal clearance explains elevated troponin $\mathrm{T}$ fragments in hemodialysis patients. Circulation. 2004 Jan 6;109(1):23-5. doi: 10.1161/01. CIR.0000109483.45211.8F.

72. Michielsen EC, Diris JH, Hackeng CM, Wodzig WK, Van Dieijen-Visser MP. Highly sensitive immunoprecipitation method for extracting and concentrating low-abundance proteins from human serum. Clin Chem. 2005 Jan;51(1):2224. doi: 10.1373/clinchem.2004.036251.

73. Cardinaels EP, Mingels AM, van Rooij T, Collinson PO, Prinzen FW, van Dieijen-Visser MP. Time-dependent degradation pattern of cardiac troponin $\mathrm{T}$ following myocardial infarction. Clin Chem. 2013 Jul;59(7):1083-90. doi: 10.1373/clinchem.2012.200543.

74. Streng AS, de Boer D, Bouwman FG, Mariman EC, Scholten A, van Dieijen-Visser MP, Wodzig WK. Development of a targeted selected ion monitoring assay for the elucidation of protease induced structural changes in cardiac troponin T. J Proteomics. 2016 Mar 16;136:123-32. doi: 10.1016/j.jprot.2015.12.028.

75. Labugger R, McDonough JL, Neverova I, Van Eyk JE. Solubilization, two-dimensional separation and detection of the cardiac myofilament protein troponin T. Proteomics. 2002 Jun;2(6):673-8. doi:10.1002/16159861(200206)2:6<673::AID-PROT673>3.0.CO;2-2.

76. deFilippi C, Seliger SL, Kelley W, Duh SH, Hise M, Christenson RH, Wolf M, Gaggin H, Januzzi J. Interpreting cardiac troponin results from high-sensitivity assays in chronic kidney disease without acute coronary syndrome. Clin Chem. 2012 Sep;58(9):1342-51. doi: 10.1373/ clinchem.2012.185322.

77. Dubin RF, Li Y, He J, Jaar BG, Kallem R, Lash JP, Makos G, Rosas SE, Soliman EZ, Townsend RR, Yang W, Go AS, Keane M, Defilippi C, Mishra R, Wolf M, Shlipak MG; CRIC Study Investigators. Predictors of high sensitivity cardiac troponin $\mathrm{T}$ in chronic kidney disease patients: a cross-sectional study in the chronic renal insufficiency cohort (CRIC). BMC Nephrol. 2013 Oct 22;14:229. doi: 10.1186/1471-2369-14229.

78. Katrukha IA, Kogan AE, Vylegzhanina AV, Serebryakova MV, Koshkina EV, Bereznikova AV, Katrukha AG. ThrombinMediated Degradation of Human Cardiac Troponin T. Clin Chem. 2017 Jun;63(6):1094-1100. doi: 10.1373/ 
clinchem.2016.266635.

79. Chaulin AM, Duplyakov DV. MicroRNAs in Atrial Fibrillation: Pathophysiological Aspects and Potential Biomarkers. International Journal of Biomedicine. 2020;10(3):198-205. doi: 10.21103/Article10(3)_RA3

80. Chaulin AM, Abashina OE, Duplyakov DV. Pathophysiological mechanisms of cardiotoxicity in chemotherapeutic agents. Russian Open Medical Journal 2020; 9: e0305. doi: 10.15275/rusomj.2020.0305

81. Chaulin AM, Duplyakov DV. [Arrhythmogenic effects of doxorubicin]. Complex Issues of Cardiovascular Diseases. 2020;9(3):69-80. doi: 10.17802/2306-1278-2020-9-3-69-80. [Article in Russian].

82. Chaulin AM, Duplyakov DV. On the potential effect of circadian rhythms of cardiac troponins on the diagnosis of acute myocardial infarction. Signa Vitae. 2021.doi:10.22514/ sv.2021.050.
83. Chaulin AM, Duplyakova PD, Duplyakov DV. Circadian rhythms of cardiac troponins: mechanisms and clinical significance. Russian Journal of Cardiology. 2020;25(3S):4061. doi: 10.15829/1560-4071-2020-4061

84. Chaulin AM, Duplyakov DV. Biomarkers of acute myocardial infarction: diagnostic and prognostic value. Part 1. Journal of Clinical Practice. 2020;11(3):75-84. doi: 10.17816/clinpract34284.

85. Chaulin AM, Abashina OE, Duplyakov DV. [Highsensitivity cardiac troponins: detection and central analytical characteristics]. Cardiovascular Therapy and Prevention. 2021;20(2):2590. doi: 10.15829/1728-8800-2021-2590. [Article in Russian].

86. Chaulin A. Cardiac Troponins: Contemporary Biological Data and New Methods of Determination. Vasc Health Risk Manag. 2021 Jun 3;17:299-316. doi: 10.2147/VHRM. S300002. PMID: 34113117 